\title{
The impact of changing family structures on the income distribution among Costa Rican women 1993-2009
}

\author{
Maximilian Kasy ${ }^{1}$ \\ Alvaro Ramos-Chaves ${ }^{2}$ \\ Harvard University, Department of Economics, Littauer Center, 1805 Cambridge Street, Cambridge, MA 02138. E-Mail: \\ maximiliankasy@fas.harvard.edu.
}

\begin{abstract}
Changes in family structures, such as the composition of households with respect to size, age and gender, can have an impact on poverty rates and the income distribution more generally. We analyze the impact of changing family structures on the income distribution among adult Costa Rican women between 1993 and 2009, using decomposition methods. There was a general increase in the share of family structures associated with lower incomes (singles with dependents) until 2001. After 2001, this trend reversed for women at the upper end of the income distribution, while it continued for women at the lower end. Correspondingly, we find a general negative effect of changing family structures on incomes of adult women until 2001, and an inequality-increasing effect after 2001. The change in trends might be due to a law coming into force in 2001 and which mandated DNA tests for presumptive fathers unwilling to recognize their children.
\end{abstract}

Keywords: income distribution, family structures

JEL: C14, D31, J12, J13, O15

\footnotetext{
${ }^{1}$ Assistant Professor, Department of Economics, Harvard University

${ }^{2}$ Vice minister of the Treasury of Costa Rica
} 


\section{Introduction}

Lone motherhood is highly correlated with poverty for women in many countries. In our data, lone mothers in Costa Rica in 2008/09 were 8.5\% more likely to be poor than women who live in households without dependents, whether or not they are the household head. ${ }^{3}$ There are several reasons for this correlation: Having more adults in a household means having more potential wage earners. Having children or other dependents such as elderly parents means that there are more people with whom the income must be shared. Having (young) children also implies that more reproductive work has to be done within the household. This in turn makes it harder for lone parents to earn a living by working outside the household. Finally, the correlation might also be due to causal effects of income levels on the likelihood of lone motherhood, or due to confounding factors. It might be the case, for instance, that poverty makes it harder to maintain stable relationships. It might also be the case that increased education increases both access to birth control and incomes.

The correlation between poverty and lone motherhood suggests that changing family structures ${ }^{4}$ might have a causal effect on the income distribution in general and poverty rates in particular. A general increase in the number of lone mothers might negatively impact incomes, for instance, and an increase of lone motherhood only at the lower end of the income distribution might increase inequality among women. The goal of this paper is to estimate the effect of changing family structures in Costa Rica, from 1993 to 2009, on the distribution of household equivalent income among adult women. Changes in the income distribution over a certain time span can be decomposed into three components, (i) changes in the distribution of equivalent incomes given family structures and demographic covariates, ${ }^{5}$ (ii) changes in the likelihood of various family structures given covariates, and (iii) changes in the distribution of demographic covariates. The counterfactual distributions we consider hold (i) and (iii) constant and isolate the effect of changing family structures. They correspond to the thought-experiment of assuming that both the demographic composition as well as the income distribution for households of a given type remained constant, but the distribution of household types changed. These counterfactual distributions describe the causal effect of changing family structures under the assumption that the family status of individuals is independent of the unobserved determinants of their income, conditional on the observed demographic covariates. The way we estimate counterfactual distributions is a logical generalization of the well known Oaxaca-Blinder decompositions. ${ }^{6}$

We find that the changes in family structure lead to an increase in the inequality of the income distribution among adult women over the period under consideration, 1993/94-2008/09. There are marked differences in the patterns of change before and after 2000/01, however. In the earlier period, the relative changes of incomes are roughly constant and negative across income levels; in the later period, higher incomes grew due to changing family structures, while lower incomes decreased further. In most subgroups we find similar effects, with the exception of urban women, where both high and low incomes were decreased more strongly than intermediate incomes by changing family structures. One plausible explanation for these findings is the "Ley de Paternidad Responsable" (Responsible Paternity Law), which was passed in 2001. This law made it much easier for lone mothers to get child support payments from the fathers, and seems to have had a considerable impact on family structures, as will be discussed in section 2 .

Diane Pearce (1978) coined the term "feminization of poverty" to describe the fact that the share of women among the poor had increased in the USA. Other researchers have proposed alternative definitions

\footnotetext{
${ }^{3}$ See Table 3 in section 3 . The number cited is the poverty rate of women living in households headed by a lone parent. A person here is defined to be poor if the equivalent income of her household lies below the poverty line defined by the National Institute of Census and Statistics of Costa Rica for that year. Equivalent income is defined as total income of a household divided by the OECD equivalent scale, see section 2. This is a narrow definition of poverty, for a discussion on its limitations see below.

4 "Family structure" here is defined in terms of houshold composition by age, gender, and the relationship between members, see section 2 .

${ }^{5}$ The covariates we use include in particular age, geographic location, and education.

${ }^{6}$ For a general overview of the literature on decompositions of income distributions see Sergio Firpo, Nicole Fortin, and Thomas Lemieux (2011).
} 
of the term "feminization of poverty," using it to describe an increase of poverty for women (in absolute terms, or relative to men), or to describe increases of the shares of either female-headed households among the poor, or the share of poor among female-headed households.

Of particular relevance to the present paper is the research presented in Sylvia Chant (2009). Chant argues that Costa Rica has indeed seen a "feminization of poverty", in the sense of a rising share of femaleheaded households among the poor. The reason for this, however, is not so much that female-headed households have become poorer, but rather that more women choose lone motherhood. She argues, based on ethnographic work, that the reason for this might be a changing legal context, in which it has become more palatable for women to choose lone motherhood, despite the monetary cost. This story seems consistent with our findings in this paper.

Studying data from various countries in Latin America, Joana Costa and Marcelo Medeiros (2008) argue there is no systematic evidence for a feminization of poverty across the countries studied. They do find strong evidence that family structures - in particular having young children - are strongly correlated with poverty, however.

There is a literature in demography discussing the relationship between family structures and the income distribution in the United States, see for instance Robert Lerman (1996), John Iceland (2003) and Molly Martin (2006). This literature is motivated by similar concerns as the present paper, but uses different methodologies. In particular, these authors do not consider counterfactual distributions holding constant the distribution of a rich set of covariates, as we do. Controlling for a large number of possible confounders allows us to more plausibly approximate causal effects of changing family structures. Andreas Peichl, Nico Pestel and Hilmar Schneider (2010) present results similar to ours in the context of German demographic developments since 1991. In contrast to our analysis, they focus on the effect of household size, while we construct a categorization of household types based on our motivation in terms of the role of lone parenthood. Our analysis is furthermore distinguished from these contributions by discussing the impact of a policy intervention (the Law of Responsible Paternity) on the income distribution via its impact on family structures, in addition to considering secular trends in demographics.

This paper draws on the literature on income decomposition techniques. Our methods build on the reweighting proposed in John DiNardo, Nicole Fortin and Thomas Lemieux (1996), as well as the influence function regression developed in Sergio Firpo, Nicole Fortin, and Thomas Lemieux (2009). ${ }^{7}$

This paper contributes to the literature in several ways. First, we make a point about the determinants of the income distribution. Market factors, such as demand shifts, trade and technological change, as well as institutional factors, such as (de)unionization and the minimum wage, have received a lot of attention in the literature. In this paper, we document how family structures play a role in determining the income distribution. Second, we provide suggestive evidence on the impact of the Ley de Paternidad Responsable. Third, we introduce readers of this journal to recent advances in econometric methodology, which allow to estimate counterfactual income distributions without relying on parametric statistical models. We also provide a comparison of two estimation methods for the impact of changes in the distribution of a determinant of incomes on the unconditional distribution of incomes: reweighting and influence function regression.

It is important to emphasize that the main focus of this paper is not to contribute to debates on the extent of gender inequality, nor to discussion around the proper definition and measurement of concepts such as poverty. Rather, we take a necessarily limited measure (household level income relative to household size), and discuss to what extent changes in the distribution of such income, for women, were caused by changes in family structures.

Our approach has a number of limitations if our object of interest is the effect of family structures on the distribution of welfare. We believe these limitations do not invalidate, nor render uninteresting, our analysis. It is however important to be aware of these limitations, which might also point to possibilities for interesting future research.

\footnotetext{
${ }^{7} \mathrm{~A}$ general discussion of issues arising in the analysis of income inequality, such as the choice of the unit of observation and income measurement can be found in Anthony Atkinson and François Bourguignon (2000). Decompositions of the household income distribution are discussed in François Bourguignon, Francisco Ferreira and Phillippe Leite (2008).
} 
First, we only analyze the distribution of income across households, not within households. Data on the distribution within households are not available, and we therefore study the distribution of equivalent household income across women. Some recent research, such as by Carmen Diana Deere, Gina Alvarado and Jennifer Twyman (2012), has studied intra-household inequality using survey responses about asset ownership. ${ }^{8}$

Second, we do not consider nonmonetary consequences of family structures on welfare, such as the division of labor in raising children or taking care of elderly family members. A large literature on the measurement of poverty has emphasized non-monetary sources of deprivation; this literature has lead in particular to the development of multidimensional indices of poverty such as the human poverty index, see for instance Sakiko Fukuda-Parr (1999) or Gita Sen (2008).

Third, we do not study the effects of family structures on adult men or children. We do this because this paper is motivated by the correlation between lone parenthood and the risk of poverty, and the fact that lone parenthood is much more common among women then men.

The rest of the paper is structured as follows: In section 2 we describe the institutional, demographic, and political background of our analysis, and the dataset that we use, the Costa Rican Household Survey by the Costa Rican National Institute of Census and Statistics. We also discuss how we define variables such as family status and equivalent income. Section 3 provides a formal discussion of our identification approach and of nonparametric decompositions of distributional change. In this section we review two estimation methods of the impact of changes in covariate distributions on the unconditional outcome distribution of interest: reweighting and influence function regression. The online appendix contains empirical results for various subpopulations defined by age, location, and education, as well as using an alternative equivalence scale.

\section{Background and data description}

\section{The "Ley de Paternidad Responsable"}

Lone mothers and their children represent a large fraction of the poor in Costa Rica. During the 1990s, the percentage of children born without a registered father rose to more than $30 \%$ of all births. Concerned by the link between childhood poverty and absent fathers, ${ }^{9}$ Congress passed the Ley de Paternidad Responsable (Responsible Paternity Law) in early 2001. The Law mandates that presumptive fathers who refuse to acknowledge their children have to submit to DNA tests in government-funded labs. Births without a registered father fell to $8 \%$ in 2002 , see Table $1 .{ }^{10}$ In Costa Rica, child support payments often exceed $25 \%$ of the father's income and are strongly enforced with garnished wages and prison for non-compliers. However, they are enforced only if the father is legally affiliated to the child, that is if he voluntarily recognized his paternity or paternity was proven by a DNA test. Hence, the Law shifted the burden of proving paternity in such a way that more resources are now allocated towards unmarried women and their children. This affected decisions of both women and men on childbearing and marital status. After the Law, there were fewer births overall and fewer births within marriage than expected by pre-Law trend. A plausible explanation of the decrease in births within marriage is that less women feel compelled to marry when they are pregnant after the law went into effect, since they are now able to obtain child support payments without marriage. This mechanism suggests that we might expect an increase in lone motherhood and a decrease in marriage rates, in line with the findings of Sylvia Chant (2009).

\footnotetext{
${ }^{8}$ We consider this interesting research, yet it is not obvious that formal or informal titles of ownership correspond to control over assets or to disposition over resulting incomes; thus it is not obvious that differences in asset ownership correspond to the aspects of inequality we most care about. More direct measures of intra-household inequality might relate to consumption and outcomes such as measures of health, literacy, or calorie intake.

${ }^{9}$ See Mónica Budowski and Luis Rosero-Bixby (2000)

${ }^{10}$ This table considers data for the 16 years before the "Ley de paternidad responsable" was passed, and for the 7 years thereafter. The first two columns show the share of each group among all new parents. The third column shows the change of the number of births within each group. Change is the change in the average number of births within a given category before and after the Law.
} 
A possible alternative explation of changing family patterns is that from 1986 to 2008, children born in Costa Rica from a Nicaraguan mother increased from $2.8 \%$ to $16 \%$. Since Nicaraguans are poorer and more likely to be unmarried than Costa Ricans, this could have been a factor affecting childbearing trends, but the fall in fertility and changes in marital status are similar even when immigration from Nicaragua is taken into account.

\section{Demographic shifts in Costa Rica}

Latin America in general and Costa Rica in particular have historically had a high fraction of births from unmarried mothers. During the 1990s, birth data show that this fraction increased significantly, and especially the fraction of children without a registered father at birth, ${ }^{11}$ see figure 1.

Figure 1: Fraction of births from unmarried mothers and of births without a registered father

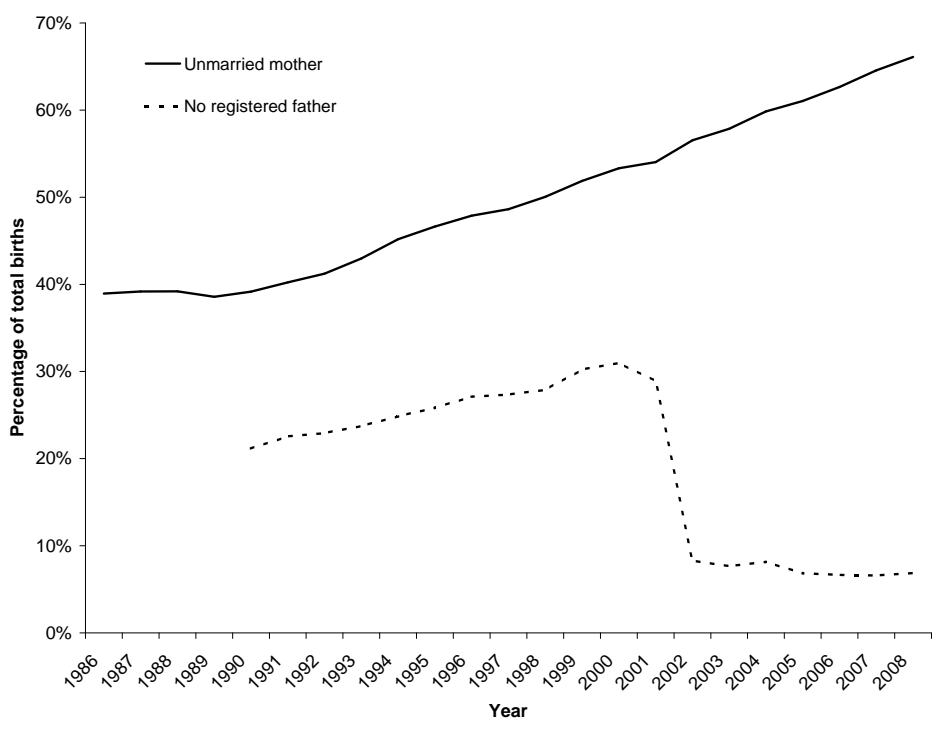

Notes: This figure shows the fraction of births from unmarried mothers and of births without a registered father, calculated using the Birth Database of the Costa Rican Institute of Census and Statistics

In Costa Rica, birthrates fell very quickly during the 1990s. Immediately following the introduction of the Law, birthrates dropped by an additional 5\%. By 2003, the birthrates were below the replacement rate (less than 2.1 children per woman over her reproductive lifetime), and the 2000s have been a period of relative stability in fertility rates, albeit at much lower levels than in the 1990s, see INEC (2008). Such large changes in fertility also lead to large changes in family structures. Since the Costa Rican population is fairly young, the rapidly decreasing number of children was not compensated by an increase in the number of dependent elderly parents, which means that the overall dependency ratio has gone down. Also, the drop in the number of young children lead to a larger percentage of childless households and of households with only adult children, who potentially contribute to household income. We explore the effects of these changes in family structures on the income distribution among women, in contrast to other studies of the income distribution in Costa Rica which have emphasized the role of education and occupational choices or social class, see Estado de la Nación (2009).

\footnotetext{
${ }^{11}$ In light of our analysis below it needs to be emphasized that lone parenthood does not always imply lone-headed households, as lone mothers may for instance live with their parents.
} 
Table 1: Summary statistics, before and after the Responsible Paternity Law

\begin{tabular}{|c|c|c|c|}
\hline & \multicolumn{2}{|c|}{ Number of Births } & \\
\hline & Before & After & \\
\hline Years & 16 & 7 & \\
\hline All Births & $1,269,215$ & 510,511 & \\
\hline \multirow[t]{3}{*}{ Births per year } & 79,326 & 72,930 & \\
\hline & \multicolumn{2}{|c|}{ Percentage of births } & \multirow[b]{2}{*}{ Change } \\
\hline & Before & After & \\
\hline \multicolumn{4}{|l|}{ Age of the mother } \\
\hline Unknown & $0.6 \%$ & $0.4 \%$ & $-33 \%$ \\
\hline 13 to 17 & $8.0 \%$ & $9.0 \%$ & $4 \%$ \\
\hline 18 to 22 & $27.4 \%$ & $29.9 \%$ & $0 \%$ \\
\hline 23 to 27 & $27.6 \%$ & $27.0 \%$ & $-10 \%$ \\
\hline 28 to 32 & $20.4 \%$ & $18.8 \%$ & $-15 \%$ \\
\hline 33 to 37 & $11.4 \%$ & $10.6 \%$ & $-14 \%$ \\
\hline 37 to 49 & $4.7 \%$ & $4.3 \%$ & $-16 \%$ \\
\hline \multicolumn{4}{|l|}{ Age of the father } \\
\hline Unknown & $25.4 \%$ & $30.2 \%$ & $9 \%$ \\
\hline 13 to 17 & $0.2 \%$ & $0.4 \%$ & $92 \%$ \\
\hline 18 to 22 & $9.3 \%$ & $10.5 \%$ & $3 \%$ \\
\hline 23 to 27 & $20.2 \%$ & $18.2 \%$ & $-17 \%$ \\
\hline 28 to 32 & $19.8 \%$ & $16.8 \%$ & $-22 \%$ \\
\hline 33 to 37 & $13.3 \%$ & $12.2 \%$ & $-16 \%$ \\
\hline 37 to 49 & $11.8 \%$ & $11.8 \%$ & $-8 \%$ \\
\hline \multicolumn{4}{|l|}{ Other characteristics } \\
\hline Urban & $42.4 \%$ & $42.8 \%$ & $-7 \%$ \\
\hline Costa Rican & $91.8 \%$ & $82.3 \%$ & $-18 \%$ \\
\hline Unmarried mother & $44.7 \%$ & $61.2 \%$ & $26 \%$ \\
\hline No registered father & $19.5 \%$ & $7.6 \%$ & $-64 \%$ \\
\hline
\end{tabular}

Notes : Source Data from the Database of Births, INEC. 
Other factors influencing the Costa Rican income distribution in this period

Another important event that might be thought to have an impact on the income distribution in Costa Rica during this period is the influx of immigrants from Nicaragua following Hurrican Mitch. In October 1998, Hurricane Mitch severely affected Honduras and Nicaragua and generated a large exogenous labor supply shock of Nicaraguan immigrants in Costa Rica, a shock noticeable in Costa Rican birth data, census data and household survey data. ${ }^{12}$ The supply push has been especially strong in those regions that share the border with Nicaragua and in the agriculture and construction economic sectors. Our previous research suggests, however, that immigration had no labor market outcome effects for nearly all working-age native subgroups in 1999, the year immediately after Mitch. The exception is the subgroup of low-education men in the border regions, who had a $-6 \%$ income decline with a $10 \%$ labor force size change, implying an income-labor elasticity of 0.6. This is lower than what has been found, for instance, by Jennifer Hunt (1992).

To conclude our discussion of the background for our question, Table 2 shows how inequality of equivalent income $^{13}$ of Costa Rican developed over the course of our study period (for details on definitions and data, see below).

Table 2: The distribution of real equivalent income of Costa Rican women 1993-2009

\begin{tabular}{lrrrrrrr}
\hline year & mean & sd & p10 & p25 & p50 & p75 & p90 \\
\hline $1993-94$ & 100 & 111 & 11 & 39 & 72 & 125 & 206 \\
$2000-01$ & 124 & 173 & 13 & 41 & 81 & 147 & 263 \\
$2008-09$ & 164 & 198 & 33 & 60 & 104 & 190 & 350 \\
\hline
\end{tabular}

Notes : Based on our own calculations, using the Encuesta de Hogares de Propósitos Múltiples. Incomes are in 1000 Colones at 2005 prices.

As can be seen from this table, average real equivalent incomes increased by $64 \%$ over this period, while the standard deviation of real equivalent incomes increased by $78 \%$. The increase in inequality is concentrated mostly in the pre-2000 period, while there is some decline of inequality in the second period (with a coefficient of variation increasing from 1.1 to 1.4 and then falling back down to 1.2).

Data

The data used in this paper come from the yearly Costa Rican Multiple-Purpose Household Surveys (Encuesta de Hogares de Propósitos Múltiples). These surveys were conducted from 1993 to 2009 by the Costa Rican National Institute of Census and Statistics (Instituto Nacional de Estadísticas y Censos INEC). Each yearly survey comprises observations between July of the previous year and July of the year it is published. Since the Fatherhood Responsibility Law was passed in April 2001, the Surveys of 2000 and 2001 (with its July 2001 cutoff) are the last pre-Law surveys.

These income surveys distinguish three sources of income for each individual: the main job, a potential secondary job and other sources of income. Based on these individual incomes, a household income is calculated. While the dataset also reports whether a household receives non-monetary income such as housing or food, we do not include such non-monetary income in our definition of household income. We impute a zero income for all individuals with missing income observations. Income observations are missing in roughly $5 \%$ of households in the sample. We calculate household equivalent income by dividing total household income by the "Oxford equivalence scale," as defined in OECD (2008). This scale assigns a value of one to the first adult of the household, a value of 0.7 to all further adults, and a value of 0.5 to all children (household members aged less than 15 years). ${ }^{14}$

\footnotetext{
${ }^{12}$ See unpublished dissertation by Alvaro Ramos-Chaves.

${ }^{13}$ Household equivalent income is calculated by dividing total household income by the Oxford equivalence scale, defined below.

${ }^{14}$ The rationale for using equivalent income is that it provides a better proxy for household well-being than per capita income, since households are able to share some consumption goods such as housing. As a robustness check we have replicated our results using per-capita income.
} 
Costa Rica had very high inflation rates over the period under consideration (more than $10 \%$ yearly on average). We discount equivalent incomes using the Central Bank of Costa Rica official deflators to obtain a "real equivalent income" variable for estimations. Every individual in the survey is assigned their households real equivalent income as our main outcome variable of interest.

\section{Defining household categories}

A major practical challenge in our analysis was the categorization of households according to their composition. In order to be useful for our purposes, such a categorization has to distinguish households according to the main determinants of equivalent income - the number of (potential) wage earners, the number of dependents, and the number of potential care-takers of dependents. The categories have to be mutually exclusive and cover all households. Given the great diversity in living arrangements, this turned out to be a larger challenge than we expected. Finally, in order to avoid estimation problems (non-overlapping support), the number of categories must not be too large. Based on these considerations, we constructed the following categorization of households:

1. Couple with at least one dependent (mostly own children), no other working-age adults or adult children.

2. Couple with at least one dependent and at least one additional working-age adult (mostly own adult children).

3. Couple with at least one adult child and no dependents, sometimes other working-age adults.

4. Lone parent as head of household with at least one extra working-age adult (mostly own adult children), possibly small children or dependents.

5. Single or Couple with no children and no dependents, sometimes there are other working-age adults.

6. Lone parent, with at least one dependent, no other working-age adults or adult children

Our population of interest are working-age women (15 to 65 years old). This includes the population of reproductive-age women (15 to 49 years old), and in particular women who are less than 28 years old, who presumably were most affected by the Responsible Paternity Law, and who show the largest drop in births following the introduction of the law. The dataset includes variables on rural/urban area, region of Costa Rica (there are six major regions), age and level of education. These are the controls we use in this paper. The survey data also include expansion factors, depending on the local district of the household, to adjust for sampling rates and response rates. We use these expansion factors throughout.

\section{Identification and estimation}

Table 3 illustrates the basic idea of our identification approach, without controlling for covariates. This table shows population shares and poverty rates for working-age women in different types of households, as defined in section 2 . The counterfactual poverty rates in the last column of this table are calculated by holding constant poverty rates for each of the three groups shown, at the level of 2008/09, while letting the population shares of the groups vary over time. Counterfactual poverty is constructed by taking the average of poverty rates in 2008/09, weighted by the changing population shares of each group. According to this decomposition, Table 3 would imply that changes in family structures led to a $0.11 \%$ increase in the female poverty rate from 1993/94 to 2000/01, and a subsequent decline of $0.4 \%$ from 2000/01 to $2008 / 09$. This adds up to an overall decline of $0.29 \%$ during the entire 1993/94 to 2008/09 period, contributing to the sizable $(7.2 \%)$ drop in actual poverty rates among working-age women. The identification and estimation approach described in section 3 below is essentially a generalization of this construction of counterfactual poverty rates. In this generalization, we (i) control for covariates, (ii) consider a finer classification of family status, as discussed in section 2, (iii) use nonparametric estimation methods, and (iv) consider the entire distribution of equivalent incomes among women instead of just the poverty rate.

Suppose we observe repeated cross-sections with i.i.d. draws from the time $t$ distributions $P^{t}$ of the variables $(Y, S, X)$, where $X$ denotes covariates such as age, education, and location and $S$ is family status 
Table 3: Population shares and poverty rates for women in different types of households

\begin{tabular}{|c|c|c|c|c|c|}
\hline & \multicolumn{3}{|c|}{ Population share } & \multicolumn{2}{|c|}{ Population Poverty rate } \\
\hline & Couples with dependents & Single with children & All others & Actual & Counterfactual \\
\hline 1993-94 & $47.8 \%$ & $20.4 \%$ & $31.8 \%$ & $27.32 \%$ & $19.41 \%$ \\
\hline 2000-01 & $46.2 \%$ & $22.7 \%$ & $31.1 \%$ & $22.99 \%$ & $19.52 \%$ \\
\hline \multirow[t]{2}{*}{ 2008-09 } & $35.7 \%$ & $24.8 \%$ & $39.5 \%$ & $19.12 \%$ & $19.12 \%$ \\
\hline & \multicolumn{3}{|c|}{ Poverty rate } & & \\
\hline 2008-09 & $20.6 \%$ & $23.5 \%$ & $15.0 \%$ & & \\
\hline
\end{tabular}

Notes: All estimates are based on the Costa Rican Household Surveys, INEC.

(household composition). The variable $Y$ denotes equivalent real income, that is, household income adjusted for household size and for inflation. We are interested in isolating the effect of historical changes in family structures on the distribution (equivalent) incomes $Y, P(Y)$, or statistics thereof, $\nu(P(Y))$. Possible choices for $\nu$ include the mean, the variance, the share below the poverty line, quantiles or the Gini coefficient.

Let $P^{1}(Y, S, X)$ in particular denote the joint distribution of $(Y, S, X)$ in period 1 (e.g., 2008/09), and $P^{0}(Y, S, X)$ the corresponding distribution in period 0 (e.g., 1993/94). Our goal is to identify the counterfactual distribution $P^{*}$ of $Y$ in which the effect of changing family structures is "undone," while holding constant the current (period 1) distribution of covariates $X$ as well as the distribution of income $Y$ given $X$ and family status $S$. The change from $P^{*}$ to $P^{1}$ will be interpreted as the causal effect of changing family structures on the female income distribution. Formally, define $P^{*}$ as

$$
P^{*}(Y):=\int_{X, S} P^{1}(Y \mid X, S) P^{0}(S \mid X) P^{1}(X) d S d X .
$$

This counterfactual distribution is constructed similarly to the counterfactual changes in the wage distribution of the United States, ascribed to changes in unionization and the minimum wage etc., which were analyzed in John DiNardo, Nicole Fortin and Thomas Lemieux (1996). This counterfactual distribution can be interpreted causally under an assumption of conditional independence. Denote $Y(S, X)$ the potential equivalent income of a woman with family status $S$ and exogenous covariates $X$. Stability of $P(Y \mid X, S)$, under changes of family structures $P(S \mid X)$, is implied by

$$
Y(s, X) \perp S \mid X \forall s,
$$

where this conditional independence is assumed to hold in time periods 0 and 1 . This assumption states that there is no self selection into family status correlated with potential income, conditional on the covariates $X$. This assumption is not unproblematic, but reasonably credible with a rich set of covariates, as we have at our disposition. ${ }^{15}$

We can rewrite the distribution $P^{*}$ as

$$
P^{*}(Y \leq y)=E^{1}\left[\mathbf{1}(Y \leq y) \theta^{*}\right]
$$

where

$$
\theta^{*}:=\frac{P^{0}(S \mid X)}{P^{1}(S \mid X)} .
$$

\footnotetext{
${ }^{15}$ Our approach would be invalid if the women in a given demographic group and in households of a given structure had systematically different earnings capacity as a consequence of changes in household composition. To take an example, this would be the case if among urban, educated women in Northern Costa Rica of age 30, the law had a systematically different effect on the marriage decisions of those with higher earnings capacity. While we can not exclude such cases on a priori grounds, we believe that the conditional independence assumption is a reasonably good working approximation in this context.
} 
Equation 3 states that $P^{*}$ is a reweighted version of the current distribution, $P^{1}$. Any counterfactual distributional characteristic $\nu$ of $P^{*}$ can be estimated based on estimates of $P^{*}$, as in John DiNardo, Nicole Fortin and Thomas Lemieux (1996). This requires estimation of the ratio (4).

Alternatively, assume for a moment that $\nu$ can be written as the expectation of a function $f$ of $Y$, $\nu=E[f(Y)]$. Then the counterfactual $\nu^{*}$ can be obtained from

$$
\nu^{1}-\nu^{*}=\iint E^{1}[f(Y) \mid X, S]\left[P^{1}(S \mid X)-P^{0}(S \mid X)\right] P^{1}(X) d S d X .
$$

In general, $\nu$ will not have this linear form but can be approximated by a linear first order expansion around $P^{1}$. This idea underlies the influence-function regression approach proposed in Sergio Firpo, Nicole Fortin, and Thomas Lemieux (2009). It requires estimation of the difference $P^{1}(S \mid X)-P^{0}(S \mid X)$ and of $E^{1}[f(Y) \mid X, S=1]$.

Corresponding to these two representations of the counterfactual $\nu^{*}$, we consider two estimation approaches; reweighting observations and influence-function regression. The reweighting approach estimates the weight $\theta^{*}$ and calculates counterfactual $\nu$ from the reweighted distribution $P^{*}$.

The influence-function regression approach is based on the first order approximation of $\nu$, as a function of $P$, around $P^{1}$ :

$$
\nu(P)=\nu\left(P^{1}\right)+\int I F\left(y ; \nu, P^{1}\right) d\left(P-P^{1}\right)(y)+R
$$

where $I F$ is the influence function of the parameter $\nu$ at $P^{1}$ and $R$ is a second order remainder term. Ignoring the remainder, this representation of $\nu$ has the linear form required for the use of the representation (5), i.e.,

$$
\nu(P) \approx E\left[\nu\left(P^{1}\right)+I F\left(Y ; \nu, P^{1}\right)\right] .
$$

We can hence calculate first order approximations to the counterfactual $\nu$ based on estimates of $P^{1}(S \mid X)-$ $P^{0}(S \mid X)$ and of $E^{1}[I F \mid X, S=1]$. For details, the reader is referred to Sergio Firpo, Nicole Fortin, and Thomas Lemieux (2009).

For either approach, we need to estimate the ratio or difference between $P^{1}(S \mid X)$ and $P^{0}(S \mid X)$, corresponding to the change in family structures within demographic groups defined by $X$. We use a multinomial logit model for the distribution of $S$ given $X$, with parameters changing over time:

$$
P^{t}(S=s \mid X)=\frac{\exp \left(X \cdot \beta^{s, t}\right)}{\sum_{s^{\prime}} \exp \left(X \cdot \beta^{s^{\prime}, t}\right)} .
$$

Based on estimates of the parameters $\beta^{s, t}$, we can calculate the weights $\theta^{*}$, as

Similarly

$$
\theta^{*}=\frac{P^{0}(S \mid X)}{P^{1}(S \mid X)}=\frac{\exp \left(X \cdot \beta^{S, 0}\right)}{\sum_{s^{\prime}} \exp \left(X \cdot \beta^{s^{\prime}, 0}\right)} \cdot \frac{\sum_{s^{\prime}} \exp \left(X \cdot \beta^{s^{\prime}, 1}\right)}{\exp \left(X \cdot \beta^{S, 1}\right)} .
$$

$$
P^{1}(S \mid X)-P^{0}(S \mid X)=\frac{\exp \left(X \cdot \beta^{S, 1}\right)}{\sum_{s^{\prime}} \exp \left(X \cdot \beta^{s^{\prime}, 1}\right)}-\frac{\exp \left(X \cdot \beta^{S, 0}\right)}{\sum_{s^{\prime}} \exp \left(X \cdot \beta^{s^{\prime}, 0}\right)} .
$$

For the influence-function regression approach, we also need estimates of $E^{1}[I F \mid X, S=1]$. We run the following regression, with full interactions between $X$ and $S$, for the sample of household observed in $2008 / 09$,

and assume $E^{1}[I F \mid X, S]=(X \times S) \cdot \beta^{I F, 1}$.

$$
I F=(X \times S) \cdot \beta^{I F, 1}+\epsilon,
$$

Note that, while the above approach is parametric, identification does not rely on the parametric choices: both the logit specification for $P(S \mid X)$ and the linear specification for $E[I F \mid X, S]$ are in fact "nonparametric" if we allow for sufficiently rich interactions and powers between the components of $X$ and $S$. Furthermore, following the arguments of Whitney Newey (1994), the choice of nonparametric estimator for this "first stage," if it is consistent, does not affect the asymptotic variance of root-n estimable parameters. This covers all our examples for $\nu$, except for the counterfactual densities. Confidence sets for all estimators are obtained by bootstrapping the entire procedure. 


\section{Results}

To give some preliminary idea about the relationship between family categories and poverty (income), Table 4 shows regressions of poverty and of log real equivalent income on the family categories, with and without controls. The omitted category in these regressions is the category of couples with dependents but no adult children. These regressions are calculated for the 2008/09 waves of the Costa Rican Household Survey.

The signs and magnitudes of the coefficients are as we would expect. In particular, households consisting of a lone head and dependents have significantly higher poverty levels and lower income relative to the baseline, while couples with adult children and no dependents are less likely to be poor and are richer on average. The coefficients on the controls are also as expected; e.g., having tertiary education significantly reduces poverty and increases income relative to other education levels.

Table 5 shows corresponding trends in the population shares of the different types of households that adult Costa Rican women live in. As can be seen from this table, there was an increase in household structures associated with higher poverty rates and lower average incomes until 2001, in particular an increase in the share of singles living with dependent children, singles living with adult children, as well as the share of larger households consisting of couples with adult children and dependents. After 2001, the share of such larger households dropped markedly, while the number of lone parents continued to rise. These numbers mask, however, considerable heterogeneity in changing family structures across different groups defined in terms of education, geographic location, etc. This heterogeneity necessitates a more careful analysis, to which we will turn now.

Figure 2 and all following figures are constructed as follows. The left column shows counterfactual changes calculated using the reweighting method described in section 3, the right column shows the analogous estimates calculated using influence function regression. The top row shows counterfactual changes over the entire period 1993/94 -2008/09, the middle row over the period 1993/94-2000/01, and the bottom row over the period 2000/01-2008/09. Every graph in these figures plots the function

$$
\frac{Q^{1}(.)-Q^{*}(.)}{Q^{1}(.)}
$$

where $Q^{1}(q)$ is the $\mathrm{q}^{\text {th }}$ quantile of the income distribution at the end of the period under consideration, and $Q^{*}(q)$ is the corresponding quantile of the counterfactual distribution which is constructed as discussed in section 3. This function gives the percentage change in income levels at different quantiles of the distribution induced by changing family structures. For instance, for $\mathrm{q}=0.5$, the graphs show the percentage change in the median income of working-age women over the period under consideration due to changing family structures. The figures also plot pointwise $95 \%$ confidence bands obtained by bootstrapping. Panels 2 and 3 show these graphs for all working age women and for rural women only, the panels in the online appendix show similar graphs for urban women, for women below 23 and women below 28 , as well as for women with and without more than primary education.

Several messages emerge from these graphs: (i) Changing family structures had an inequality-increasing effect for working age Costa Rican women over the period 1993-2009, leaving median incomes unchanged. (ii) This inequality increasing effect came in particular from changes in the period after 2000/01, i.e., after the Responsible Paternity Law was introduced. In contrast, the changes in the period prior to 2000/01 had a negative effect on equivalent incomes across the entire income distribution. (iii) The inequality increasing effect was particularly strong among rural women. (iv) The changing family structures after 2000/01 had a particularly positive effect for younger women, except for the lowest income groups.

One possible interpretation of these results is that the general trend towards lone parenthood adversely affected female equivalent incomes across the distribution prior to 2000/01, but that the Responsible Paternity Law was effective in stopping this trend. We would expect the law to affect, in particular, younger women, who are the most likely to bear children - consistent with the results shown in the online appendix. It appears, however, that the law was not effective in reversing trends at the bottom end of the income distribution. Regarding the apparent lack of a positive effect of the law on poor rural women's household 
Table 4: The impact of family structures on poverty rates and real equivalent income

\begin{tabular}{|c|c|c|c|c|}
\hline & $\begin{array}{c}(1) \\
\text { Poverty }\end{array}$ & $\begin{array}{c}(2) \\
\text { Poverty }\end{array}$ & $\begin{array}{c}(3) \\
\text { Income }\end{array}$ & $\begin{array}{c}(4) \\
\text { Income }\end{array}$ \\
\hline Couple w/adult children, dependents & $\begin{array}{c}0.037 \\
(0.008)\end{array}$ & $\begin{array}{c}0.032 \\
(0.007)\end{array}$ & $\begin{array}{l}-0.105 \\
(0.018)\end{array}$ & $\begin{array}{l}-0.074 \\
(0.015)\end{array}$ \\
\hline Couple w/adult children, no dependents & $\begin{array}{l}-0.043 \\
(0.007)\end{array}$ & $\begin{array}{l}-0.012 \\
(0.007)\end{array}$ & $\begin{array}{c}0.242 \\
(0.018)\end{array}$ & $\begin{array}{c}0.081 \\
(0.015)\end{array}$ \\
\hline Single w/adult children & $\begin{array}{c}0.039 \\
(0.008)\end{array}$ & $\begin{array}{c}0.056 \\
(0.008)\end{array}$ & $\begin{array}{l}-0.101 \\
(0.018)\end{array}$ & $\begin{array}{c}-0.186 \\
(0.016)\end{array}$ \\
\hline Childless households & $\begin{array}{l}-0.019 \\
(0.009)\end{array}$ & $\begin{array}{c}0.004 \\
(0.009)\end{array}$ & $\begin{array}{c}0.399 \\
(0.024)\end{array}$ & $\begin{array}{c}0.218 \\
(0.020)\end{array}$ \\
\hline Single w/dependents & $\begin{array}{c}0.119 \\
(0.017)\end{array}$ & $\begin{array}{c}0.131 \\
(0.016)\end{array}$ & $\begin{array}{l}-0.223 \\
(0.042)\end{array}$ & $\begin{array}{l}-0.305 \\
(0.033)\end{array}$ \\
\hline Age & & $\begin{array}{c}-0.004 \\
(0.001)\end{array}$ & & $\begin{array}{c}0.010 \\
(0.002)\end{array}$ \\
\hline $\mathrm{Age}^{2}$ & & $\begin{array}{c}4.4 \times 10^{-5} \\
\left(1.4 \times 10^{-5}\right)\end{array}$ & & $\begin{array}{c}4.3 \times 10^{-5} \\
\left(2.9 \times 10^{-5}\right)\end{array}$ \\
\hline Primary Education & & $\begin{array}{l}-0.145 \\
(0.017)\end{array}$ & & $\begin{array}{c}0.253 \\
(0.031)\end{array}$ \\
\hline Secondary Education & & $\begin{array}{l}-0.256 \\
(0.017)\end{array}$ & & $\begin{array}{c}0.650 \\
(0.031)\end{array}$ \\
\hline Tertiary Education & & $\begin{array}{l}-0.326 \\
(0.018)\end{array}$ & & $\begin{array}{l}1.340 \\
(0.033)\end{array}$ \\
\hline Rural & & $\begin{array}{c}0.065 \\
(0.005)\end{array}$ & & $\begin{array}{l}-0.223 \\
(0.010)\end{array}$ \\
\hline Constant & $\begin{array}{c}0.187 \\
(0.005) \\
\end{array}$ & $\begin{array}{c}0.440 \\
(0.026) \\
\end{array}$ & $\begin{array}{l}11.521 \\
(0.014) \\
\end{array}$ & $\begin{array}{l}10.836 \\
(0.051)\end{array}$ \\
\hline$N$ & 32171 & 32171 & 31300 & 31300 \\
\hline Region controls & No & Yes & No & Yes \\
\hline
\end{tabular}

Notes: Calculated using the 2008/09 waves of the Costa Rican Household Survey. 
Table 5: Population shares of different household categories for adult women over time

\begin{tabular}{lrrr}
\hline \hline & $1993-94$ & $2000-01$ & $2008-09$ \\
\hline couples with dependents, no others & $23.2 \%$ & $20.6 \%$ & $17.2 \%$ \\
Couple w/adult children, dependents & $24.6 \%$ & $25.5 \%$ & $18.5 \%$ \\
Couple w/adult children, no dependents & $23.6 \%$ & $22.8 \%$ & $28.5 \%$ \\
Single w/adult children & $18.1 \%$ & $20.1 \%$ & $22.0 \%$ \\
Childless households & $8.2 \%$ & $8.4 \%$ & $11.0 \%$ \\
Single w/dependents & $2.2 \%$ & $2.7 \%$ & $2.8 \%$ \\
\hline \hline
\end{tabular}

Notes: Calculated using the Costa Rican Household Survey.

incomes, one possible explanation might be that the family structures of poor rural women were not affected by the law, as they might not have been well informed about their rights. This seems unlikely given that immediately after birth all women are told about their rights, and given that the government pays for the DNA tests. Another explanation, which seems more plausible, is that in the presence of strong assortative mating, the fathers of poor rural women's children tend to also be poor and to have irregular and low earnings. As a consequence their potential presence in the household might have a limited impact in reducing poverty.

Methodologically, another interesting feature of our results lies in the comparison of the estimates obtained using reweighting with those obtained using influence function regression. Both methods yield very similar point estimates, which increases our confidence in the robustness of the results. It appears that the method based on influence function regression generally leads to tighter confidence bands and produces smoother estimates across quantiles. This difference in finite sample performance stands in contrast to the asymptotic equivalence, in the case of linear $\nu$, suggested by the arguments of Whitney Newey (1994). On the other hand, the use of a first order approximation in the influence function regression approach leads to a bias since higher order terms are ignored. In our case, given the small size of the counterfactual changes in the distribution, this bias is likely to be negligible, though. In combination, these observations suggest a possible bias-variance trade-off in the use of reweighting versus influence function regression. 
Figure 2: Counterfactual changes of the income distribution among all Costa Rican women

(a) Reweighting, 1993/94-2008/09

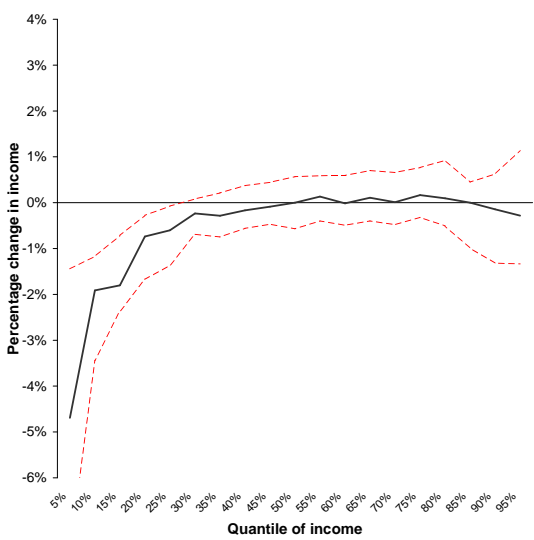

(c) Reweighting, 1993/94-2000/01

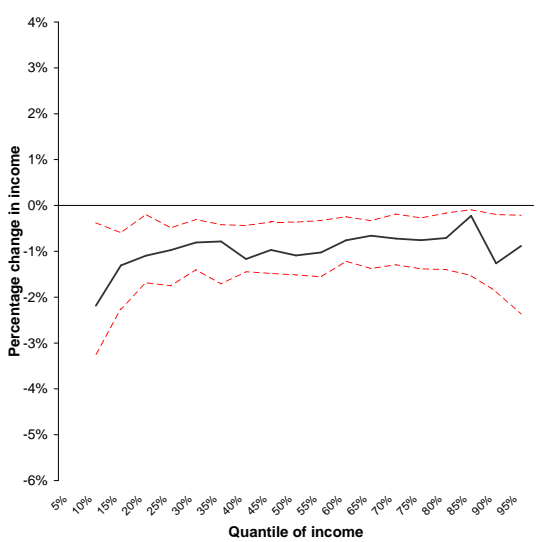

(e) Reweighting, 2000/01-2008/09

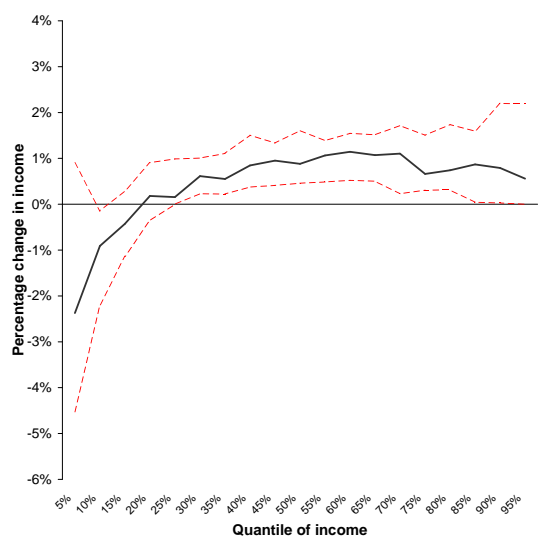

(b) Regression, 1993/94-2008/09

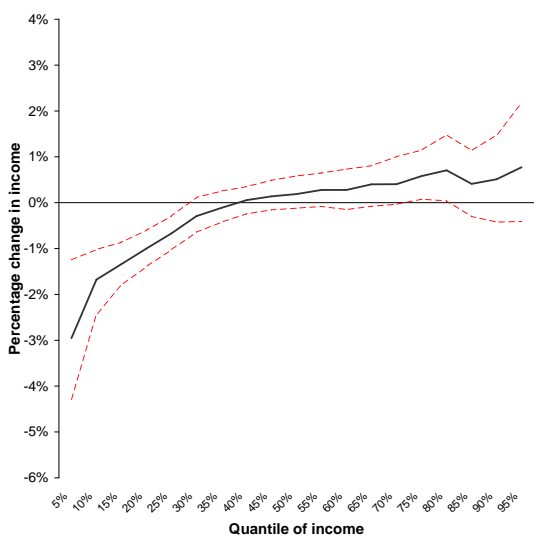

(d) Regression, 1993/94-2000/01

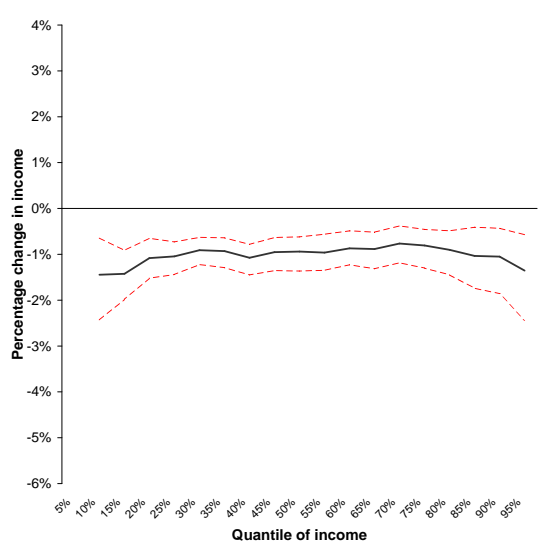

(f) Regression, 2000/01-2008/09

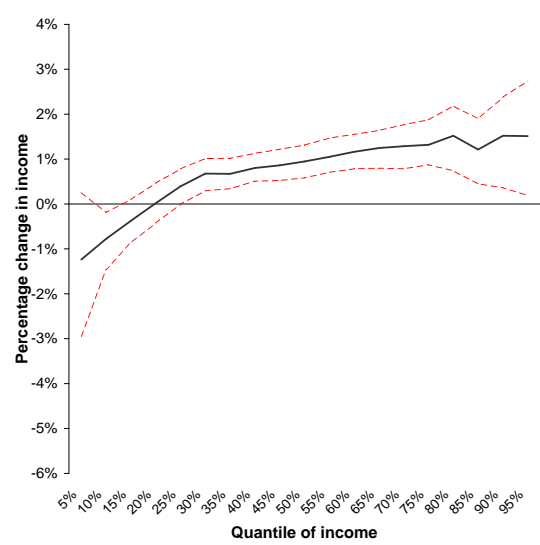


Figure 3: Counterfactual changes of the income distribution among rural women

(a) Reweighting, 1993/94-2008/09

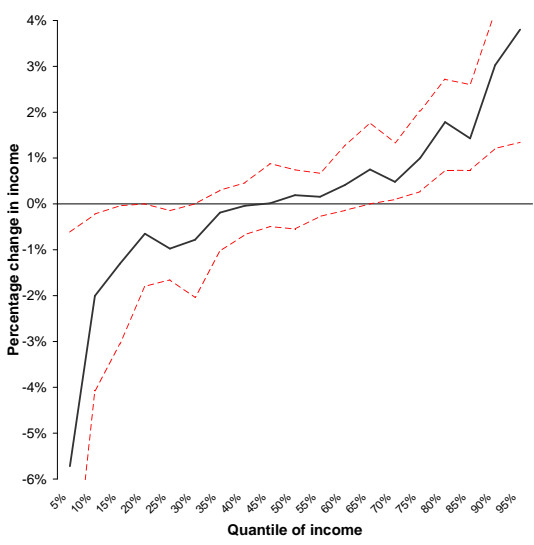

(c) Reweighting, 1993/94-2000/01

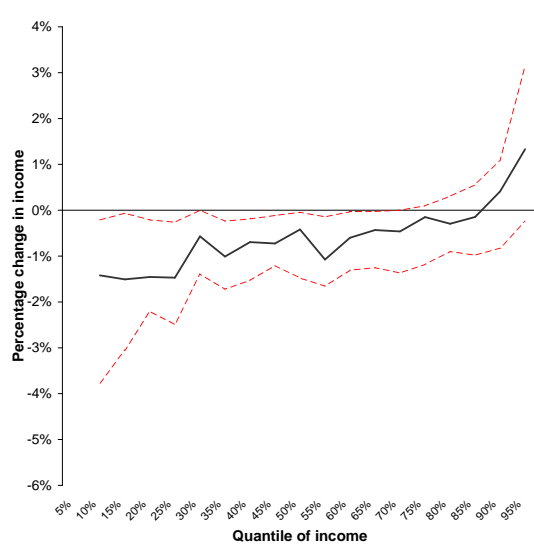

(e) Reweighting, 2000/01-2008/09

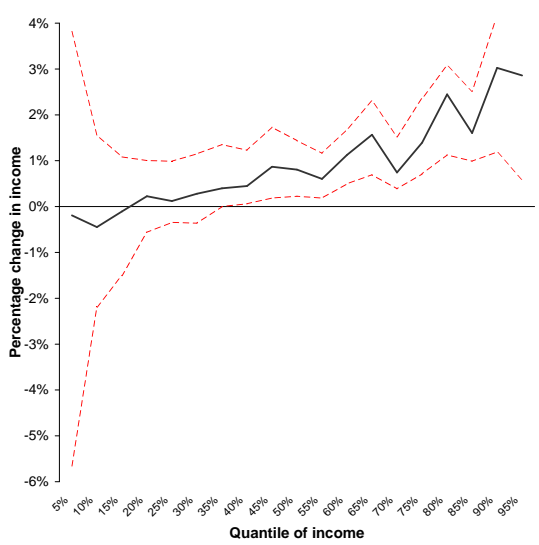

(b) Regression, 1993/94-2008/09

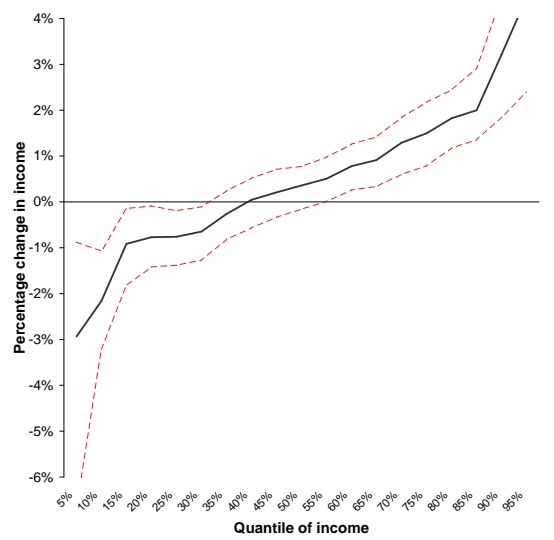

(d) Regression, 1993/94-2000/01

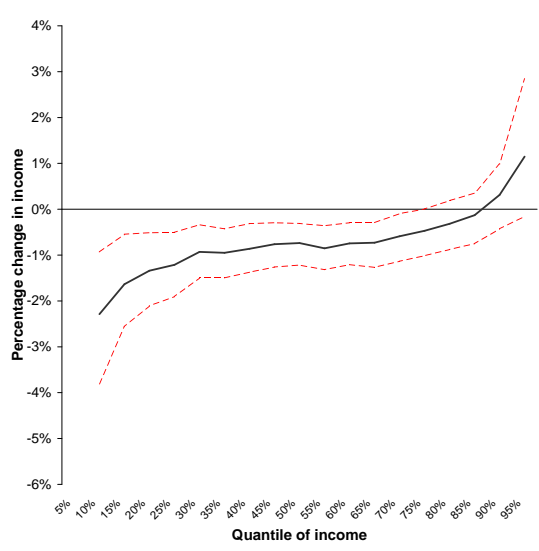

(f) Regression, 2000/01-2008/09

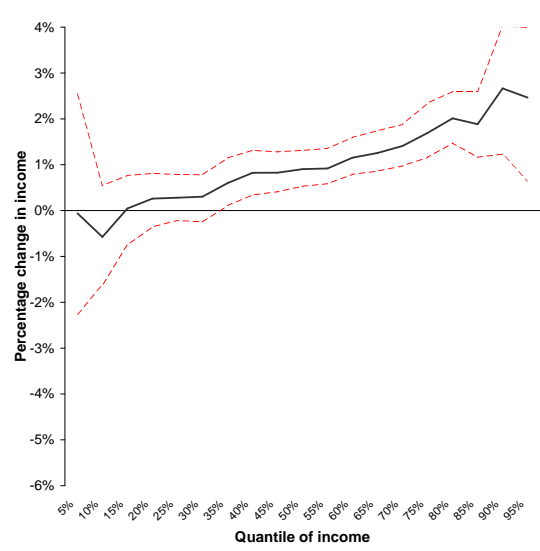




\section{Conclusion}

In this paper, we have studied the effect of changing family structures on the female income distribution in Costa Rica between 1993 and 2009. There was an increase in household structures associated with higher poverty rates and lower average incomes until 2001, in particular an increase in the share of lone parents and the share of larger households. After 2001, the share of such larger households dropped markedly, while the number of lone parents continued to rise. These numbers mask considerable heterogeneity in changing family structures across different groups. The trend towards lone parenthood continued for women at the lower end of the income distribution, while it was reversed for women at the upper end of the distribution.

We find that changing family structures had an inequality-increasing effect for working-age Costa Rican women over this period, in particular due to changes in the period after 2000/01, i.e., after the Responsible Paternity Law was introduced. Changes in the period prior to 2000/01 had a negative effect on equivalent incomes across the entire income distribution. The inequality-increasing effect was particularly strong among rural women, while the changes in family structures after 2000/01 had a particularly positive effect for younger women, except for the lowest income groups. In terms of magnitude, note that our results imply increases or decreases of incomes, due to changing family structures, at various quantiles ranging from $-2 \%$ to $+2 \%$. This contrasts with growth rates of median incomes of $13 \%$ over the period 1993/94-2000/01, and $28 \%$ over the second period. Relative to such magnitudes, changing family structures arguably played an important, but not a decisive role in shaping the economic status of women in Costa Rica over the period under consideration.

Our results illustrate the role of family structures in the determination of the distribution and level of incomes. These results imply, in particular, that various policies affecting family structures also have an important distributional effect. Such policies include policies related to family planning, the public provision of child care, retirement systems for the elderly, and marriage, divorce, and child support legislation. It is an interesting area for future research to explore the effects of such policies on the income distribution.

In a comparison of the reweighting and influence function regression methods proposed in DiNardo et al (1996) and Firpo et al (2009), we find that the influence-function technique gives smoother results with narrower confidence bands. This is contrasted by a potential bias in influence function regression, since it is based upon a first-order approximation, suggesting a potential bias-variance trade-off between the two methods. A valuable extension of the research presented in this paper might be a combination of the distributional decomposition methods discussed with credible estimates of the structural relationship between child support legislation and household composition. Such a combination would allow to assess the distributional impact of the Responsible Paternity Law, and open interesting methodological perspectives for distributional policy evaluation.

In terms of the implications for policy, we would conclude that the combination of strong child support legislation and mandatory DNA testing, as introduced in Costa Rica in 2001, had a positive effect, if we evaluate it in terms of its impact on poverty among women. The positive effect was smaller at the lower end of the income distribution. This positive effect of course stands in the context of larger general increases in inequality and rising average incomes. In such a context, legislation such as the "Ley de Paternidad Responsable" cannot substitute for other social policy measures targeted at reducing inequality and poverty. 
Anthony Atkinson and François Bourguignon, 2000. Introduction: Income distribution and economics. Handbook of income distribution 1, 1-58.

François Bourguignon, Francisco Ferreira and Phillippe Leite, 2008. Beyond oaxaca-blinder: Accounting for differences in household income distributions. Journal of Economic Inequality 6, 117-148.

Mónica Budowski and Luis Rosero-Bixby, 2000. La Costa Rica sin padres: el reconocimiento de la paternidad y la pensión alimentaria. In: Población del Istmo 2000: Familia, migración, violencia y medio ambiente. Universidad de Costa Rica, Ch. 7, pp. 105-140.

Sylvia Chant, 2009. The feminisation of poverty in Costa Rica: To what extent a conundrum? Bulletin of Latin American Research 28 (1), 19-43.

Joana Costa and Marcelo Medeiros, 2008. Is there a feminization of poverty in latin america? World Development 36 (1), $115-127$.

Carmen Diana Deere, Gina Alvarado and Jennifer Twyman, 2012. Gender inequality in asset ownership in latin america: female owners vs household heads. Development and Change 43 (2), 505-530.

John DiNardo, Nicole Fortin and Thomas Lemieux, 1996. Labor market institutions and the distribution of wages, 1973-1992: A semiparametric approach. Econometrica 64, 1001-1044.

Estado de la Nación, 2009. Decimoquinto Informe Estado de la Nación en Desarollo Humano Sostenible. Vol. 15. Programa Estado de la Nación.

Sergio Firpo, Nicole Fortin, and Thomas Lemieux, 2009. Unconditional quantile regressions. Econometrica 77, 953-973.

Sergio Firpo, Nicole Fortin, and Thomas Lemieux, 2011. Decomposition methods in economics. Handbook of Labor Economics 4, 1-102.

Sakiko Fukuda-Parr, 1999. What does feminization of poverty mean? it isn't just lack of income. Feminist Economics 5 (2), $99-103$.

Jennifer Hunt, April 1992. The impact of the 1962 repatriates from Algeria on the French labor market. Industrial and Labor Relations Review 45 (3), 556-572.

John Iceland, August 2003. Why poverty remains high: the role of income growth, economic inequality, and changes in family structure, 1949-1999. Demography 40 (3), 499-519.

INEC, September 2008. Estimaciónes y proyecciones de población por sexo y edad (cifras actualizadas) 1950-2050. Tech. rep., Instituto Nacional de Estadística y Censos (Costa Rica), San José, Costa Rica.

Robert Lerman, 1996. The impact of the changing us family structure on child poverty and income inequality. Economica 63 (250), S119-S139.

Molly Martin, August 2006. Family structure and income inequality in families with children 1976 to 2000. Demography 43 (3), 421-445.

OECD, 2008. What are equivalence scales? Tech. rep., Organization for Economic Co-operation and Development.

Diane Pearce, 1978. The feminization of poverty: women, work, and welfare. Urban and social change review.

Andreas Peichl, Nico Pestel and Hilmar Schneider, February 2010. Does size matter? the impact of changes in household structure on income distribution in germany. IZA Discussion Paper No.4770.

Gita Sen, 2008. Poverty as a gendered experience: The policy implications. Poverty in Focus: Gender Equality 13 , 6-7.

Whitney Newey, 1994. The asymptotic variance of semiparametric estimators. Econometrica 62, 1349-1382. 